\title{
Article \\ Effect of Essential Oils on the Inhibition of Biofilm and Quorum Sensing in Salmonella enteritidis 13076 and Salmonella typhimurium 14028
}

\author{
Yuliany Guillín ${ }^{1}$, Marlon Cáceres ${ }^{2}$, Rodrigo Torres ${ }^{3}$, Elena Stashenko ${ }^{4}$ and Claudia Ortiz ${ }^{5, *}$ \\ 1 Escuela de Biología, Universidad Industrial de Santander, Bucaramanga 680002, Colombia; \\ yuliany2208193@correo.uis.edu.co \\ 2 Escuela de Medicina, Universidad Industrial de Santander, Bucaramanga 680002, Colombia; \\ marlon2127899@correo.uis.edu.co \\ 3 Grupo de Investigación en Bioquímica y Microbiología, Bucaramanga 680002, Colombia; \\ rodrigotorres4@hotmail.com \\ 4 Centro de Cromatografía y Espectrometría de Masas, CROM-MASS-CENIVAM, Facultad de Ciencias, \\ Universidad Industrial de Santander, Bucaramanga 680002, Colombia; elenastashenko@gmail.com \\ 5 Escuela de Microbiología y Bioanálisis, Universidad Industrial de Santander, Bucaramanga 680002, Colombia \\ * Correspondence: ortizc@uis.edu.co
}

check for updates

Citation: Guillín, Y.; Cáceres, M.; Torres, R.; Stashenko, E.; Ortiz, C. Effect of Essential Oils on the Inhibition of Biofilm and Quorum Sensing in Salmonella Enteritidis 13076 and Salmonella Typhimurium 14028. Antibiotics 2021, 10, 1191. https://doi.org/10.3390/ antibiotics10101191

Academic Editors: William N. Setzer and Noura Dosoky

Received: 27 August 2021

Accepted: 25 September 2021

Published: 1 October 2021

Publisher's Note: MDPI stays neutral with regard to jurisdictional claims in published maps and institutional affiliations.

Copyright: (c) 2021 by the authors. Licensee MDPI, Basel, Switzerland. This article is an open access article distributed under the terms and conditions of the Creative Commons Attribution (CC BY) license (https:/ / creativecommons.org/licenses/by/ $4.0 /)$.

\begin{abstract}
The emergence of multidrug-resistant microorganisms represents a global challenge that has led to a search for new antimicrobial compounds. Essential oils (EOs) from medicinal aromatic plants are a potential alternative for conventional antibiotics. In this study, the antimicrobial and anti-biofilm potential of $15 \mathrm{EOs}$ was evaluated on planktonic and biofilm-associated cells of Salmonella enterica serovar Enteritidis ATCC 13076 (S. enteritidis) and Salmonella enterica serovar Typhimurium ATCC 14028 (S. typhimurium). In total, 4 out of 15 EOs showed antimicrobial activity and 6 EOs showed anti-biofilm activity against both strains. The EO from the Lippia origanoides chemotype thymol-carvacrol II (LTC II) presented the lowest minimum inhibitory concentration $\left(\mathrm{MIC}_{50}=0.37 \mathrm{mg} \mathrm{mL}^{-1}\right)$ and minimum bactericidal concentration $\left(\mathrm{MBC}=0.75 \mathrm{mg} \mathrm{mL}^{-1}\right)$ values. This EO also presented the highest percentage of biofilm inhibition $(>65 \%)$ on both microorganisms, which could be confirmed by scanning electron microscopy (SEM) images. Transcriptional analysis showed significant changes in the expression of the genes related to quorum sensing and the formation of the biofilm. EOs could inhibit the expression of genes involved in the quorum sensing mechanism $(l u x R, l u x S, q s e B, \operatorname{sdi} A)$ and biofilm formation $(\operatorname{csg} A, \operatorname{csg} B, \operatorname{csg} D, f l h D, f l i Z$, and $m o t B$ ), indicating their potential use as anti-biofilm antimicrobial agents. However, further studies are needed to elucidate the action mechanisms of essential oils on the bacterial cells under study.
\end{abstract}

Keywords: essential oils; biofilm; Salmonella; antimicrobials; RT-qPCR

\section{Introduction}

Non-typhoidal salmonellosis is one of the most relevant zoonotic diseases across the globe due to the fact that it affects human and animal health [1]. Around 93 million people are infected by bacteria of the Salmonella genus and 155,000 die from this pathogen each year [2]. Salmonella is spread through the consumption of contaminated food or water and contact with infected people or animals [3]. Salmonella species are etiological agents of intestinal and systemic infections, the most frequent being gastroenteritis, bacteremia, an asymptomatic chronic carrier state, or localized infection [4]. Recently, the World Health Organization (WHO), the Food and Agriculture Organization of the United Nations (FAO), and the Center for Disease Control and Prevention (CDC) reported an increase in antibiotic resistance in Salmonella strains due to the indiscriminate use of conventional bactericides [5,6]. Consequently, some infections that were controlled a few decades ago now reoccur with multi-resistant microorganisms [7]. 
Antimicrobial multi-resistance is developed through various natural (family-specific) or acquired mechanisms (including horizontal gene transfer, gene deletions, and mutations) $[8,9]$. Several studies have shown that different Salmonella species are able to form biofilm through different types of chemical cell communication [10,11]. Thus, Salmonella is associated with different persistent hospital infections, especially in the immunocompromised population [12]. Biofilms are microbial communities made up of sessile cells irreversibly attached to a substrate, embedded in an extracellular polymer matrix produced by themselves [13]. Because the biofilm formed by Salmonella is resistant to environmental stress factors (e.g., low water activity or the presence of disinfectants), this state of cellular organization probably contributes to the survival of the microorganism outside the host and to the infection of new hosts [14]. Thus, the biofilm gives the microorganism increased resilience, inhibiting the bactericidal effect of antibiotics $[15,16]$. In addition, different studies have demonstrated the ability of Salmonella to form a biofilm on abiotic surfaces, such as plastic, rubber, cement, glass, and stainless steel $[17,18]$. Therefore, the search for new effective antimicrobial alternatives against resistant pathogens has received a significant increase in attention. During the last few years, numerous studies have been published, widely demonstrating the antimicrobial activity of EOs, which could have an important therapeutic potential due to their both high content and diversity of chemical compounds such as aldehydes, phenols, and terpenes [19-21]. This feature enables a wide spectrum of action on different microorganisms as well as multiple effects, such as the inhibition of quorum sensing $(\mathrm{QS})$, the prevention of biofilm formation, and the inhibition of the growth of resistant microorganisms [22].

In this study, we aimed to determine the antimicrobial and anti-biofilm activity of 15 EOs on Salmonella enterica serovar Enteritidis ATCC 13076 and Salmonella enterica serovar Typhimurium ATCC 14028. In addition, the differential expression of some genes involved in quorum sensing and biofilm formation was measured by RT-qPCR to determine the potential anti-QS effect of EOs.

\section{Results}

\subsection{Determination of the In Vitro Antimicrobial Activity of EOs on Planktonic Cells}

The results of $\mathrm{MIC}_{50}$ and $\mathrm{MBC}$ are presented in Table 1. Four of the evaluated EOs (CM, LTC I, LTC II, and TV) presented inhibitory activity against the bacterial strains under study. The $\mathrm{MIC}_{50}$ values varied between 0.37 and $0.75 \mathrm{mg} \mathrm{mL}^{-1}$ and the $\mathrm{MBC}$ values between 0.75 and $1.5 \mathrm{mg} \mathrm{mL}^{-1}$. The EO showing the lowest $\mathrm{MIC}_{50}$ and $\mathrm{MBC}$ values against $S$. typhimurium and S. enteritidis was LTC II ( $\mathrm{MIC}_{50}=0.37 \mathrm{mg} \mathrm{mL}^{-1} ; \mathrm{CMB}=0.75 \mathrm{mg} \mathrm{mL}^{-1}$ ), which also had the highest content of thymol and carvacrol [23]. The LTC I EO showed a similar antimicrobial activity to LTC II on S. enteritidis ( $\mathrm{MIC}_{50}=0.37 \mathrm{mg} \mathrm{mL}^{-1} ; \mathrm{CMB}=0.75 \mathrm{mg} \mathrm{mL}^{-1}$ ), and both $\mathrm{MIC}_{50}$ and $\mathrm{CMB}$ values were increased in S. typhimurium ( $\mathrm{MIC}_{50} 0.75 \mathrm{mg} \mathrm{mL}^{-1}$ and $\mathrm{CMB}$ $1.5 \mathrm{mg} \mathrm{mL}^{-1}$ ). The TV and CM EOs presented an $\mathrm{MIC}_{50}$ of $0.75 \mathrm{mg} \mathrm{mL}^{-1}$ and a CMB $1.5 \mathrm{mg} \mathrm{mL}-1$ on both Salmonella strains. Regarding their chemical composition, EOs from LTC I, LTC II, and TV had a high content of phenolic compounds, such as thymol (the compound with the highest proportion in the three EOs) and carvacrol, as well as oxygenated monoterpenes and sesquiterpene hydrocarbons, such as $p$-cymene and trans- $\beta$-caryophyllene, respectively. Moreover, the EO from $\mathrm{CM}$ showed a high content of oxygenated monoterpenes, such as geraniol and linalool. The antimicrobial activities of the mentioned compounds have been mainly attributed to their interaction with the lipid bilayer of the cytoplasmic membranes, which is involved in the loss of integrity and the leakage of cellular material, such as DNA, ATP, or ions from bacterial cells [24].

\subsection{In Vitro Inhibition of Biofilm Formation}

Inhibition of biofilm was performed for the $15 \mathrm{EOs}$; however, essential oils that presented antimicrobial activity were evaluated at sub-inhibitory concentrations. The results are expressed as the percentage of inhibition (Table 2). EOs from LTC I, LTC II, and TV had the lowest minimum inhibitory concentrations in biofilm (MICB) on both Salmonella 
strains, with a percentage of inhibition of biofilm formation higher than $60 \%$ (Figure 1). For these EOs, the inhibition of biofilm formation could be attributed to the activity of the different oxygenated compounds and their ability to diffuse through the exopolysaccharide matrix (EPS), destabilizing it due to its intrinsic antimicrobial characteristics [25]. Other EOs, such as the AE of CM and TL, inhibited the formation of biofilm of S. enterica and S. typhimurium by up to $60 \%$, although only the EO from CM exhibited antimicrobial activity. The LOF EO only showed anti-biofilm activity against $S$. enteritidis, inhibiting the formation of biofilm by $64.38 \%$ (MICB $=1.5 \mathrm{mg} \mathrm{mL}^{-1}$ ). Despite not showing any antimicrobial activity, the LOF and TL EOs could have the potential to be used as antibiofilm agents.

Table 1. Minimum inhibitory concentration $\left(\mathrm{MIC}_{50}\right)$ and minimum bactericidal concentration (MBC) of the $15 \mathrm{EOs}$ on S. typhimurium ATCC 14028 and S. enteritidis ATCC 13076. Each experiment was carried out in triplicate. Data are represented as mean $\pm \mathrm{SD}$.

\begin{tabular}{|c|c|c|c|c|c|}
\hline \multirow{2}{*}{\multicolumn{2}{|c|}{ Essential Oils }} & \multicolumn{4}{|c|}{ Antimicrobial } \\
\hline & & \multicolumn{2}{|c|}{ S. typhimurium } & \multicolumn{2}{|c|}{ S. enteritidis } \\
\hline Code & & $\mathrm{MIC}_{50}$ & MBC & $\mathrm{MIC}_{50}$ & $\mathrm{MBC}$ \\
\hline code & Plant & \multicolumn{4}{|c|}{$\mathrm{mg} \mathrm{mL}^{-1}$} \\
\hline LACA & Lippia alba (Mill.) (carvona) & $>1.5$ & $>1.5$ & $>1.5$ & $>1.5$ \\
\hline LACI & L. alba (citral) & $>1.5$ & $>1.5$ & $>1.5$ & $>1.5$ \\
\hline $\mathrm{CN}$ & Cymbopogon nardus (L.) & $>1.5$ & $>1.5$ & $>1.5$ & $>1.5$ \\
\hline $\mathrm{CM}$ & C. martini (Roxb.) & $0.75 \pm 0.07$ & $1.5 \pm 0.01$ & $0.75 \pm 0.02$ & $1.5 \pm 0.04$ \\
\hline CF & C. flexuosus (Nees ex Steud.) & $>1.5$ & $>1.5$ & $>1.5$ & $>1.5$ \\
\hline LTC I & L. origanoides (Kunth) (thymol-carvacrol I) & $0.75 \pm 0.16$ & $1.5 \pm 0.05$ & $0.37 \pm 0.02$ & $0.75 \pm 0.03$ \\
\hline LTC II & L. origanoides (thymol-carvacrol II) & $0.37 \pm 0.08$ & $0.75 \pm 0.06$ & $0.37 \pm 0.03$ & $0.75 \pm 0.02$ \\
\hline LOF & L. origanoides (phellandrene) & $>1.5$ & $>1.5$ & $>1.5$ & $>1.5$ \\
\hline $\mathrm{RO}$ & Rosmarinus officinalis (L.) & $>1.5$ & $>1.5$ & $>1.5$ & $>1.5$ \\
\hline $\mathrm{SO}$ & Salvia officinalis (L.) & $>1.5$ & $>1.5$ & $>1.5$ & $>1.5$ \\
\hline SG & Swinglea glutinosa (Blanco) & $>1.5$ & $>1.5$ & $>1.5$ & $>1.5$ \\
\hline $\mathrm{TL}$ & Tagetes lucida (Cav.) & $>1.5$ & $>1.5$ & $>1.5$ & $>1.5$ \\
\hline TV & Thymus vulgaris (L.) & $0.75 \pm 0.05$ & $1.5 \pm 0.03$ & $0.75 \pm 0.02$ & $1.5 \pm 0.05$ \\
\hline SV & Satureja viminea (L.) & $>1.5$ & $>1.5$ & $>1.5$ & $>1.5$ \\
\hline $\mathrm{CO}$ & Cananga odorata (Lam.) & $>1.5$ & $>1.5$ & $>1.5$ & $>1.5$ \\
\hline
\end{tabular}

Table 2. Effect of EOs on biofilm formation by S. typhimurium ATCC 14028 and S. enteritidis ATCC 13076. Inhibition percentages were calculated with respect to the control (biofilms not treated with EOs). Each experiment was carried out in triplicate. Data are represented as mean \pm SD.

\begin{tabular}{|c|c|c|c|c|c|}
\hline \multirow{2}{*}{\multicolumn{2}{|c|}{ Essential Oils }} & \multicolumn{4}{|c|}{ Anti-Biofilm } \\
\hline & & \multicolumn{2}{|c|}{ S. typhimurium } & \multicolumn{2}{|c|}{ S. enteritidis } \\
\hline \multirow[b]{2}{*}{ Code } & \multirow[b]{2}{*}{ Plant } & MICB & Inhibition (\%) & MICB & Inhibition $(\%)$ \\
\hline & & \multicolumn{4}{|c|}{$\mathrm{mg} \mathrm{mL} \mathrm{m}^{-1}$} \\
\hline LACA & Lippia alba (Mill.) (carvona) & $>1.5$ & ND & $>1.5$ & \\
\hline LACI & L. alba (citral) & $>1.5$ & ND & $>1.5$ & ND \\
\hline $\mathrm{CN}$ & Cymbopogon nardus (L.) & $>1.5$ & ND & $>1.5$ & ND \\
\hline $\mathrm{CM}$ & C. martini (Roxb.) & $0.37 \pm 0.02$ & $50.87 \pm 0.04$ & $0.37 \pm 0.10$ & $46.72 \pm 0.05$ \\
\hline $\mathrm{CF}$ & C. flexuosus (Nees ex Steud.) & $>1.5$ & ND & $>1.5$ & ND \\
\hline LTC I & L. origanoides (Kunth) (thymol-carvacrol I) & $0.18 \pm 0.01$ & $62.18 \pm 0.06$ & $0.18 \pm 0.01$ & $61.32 \pm 0.08$ \\
\hline LTC II & L. origanoides (thymol-carvacrol II) & $0.18 \pm 0.18$ & $66.64 \pm 0.08$ & $0.18 \pm 0.08$ & $65.64 \pm 0.01$ \\
\hline LOF & L. origanoides (phellandrene) & $>1.5$ & ND & $1.5 \pm 0.06$ & $64.38 \pm 0.03$ \\
\hline $\mathrm{RO}$ & Rosmarinus officinalis (L.) & $>1.5$ & ND & $>1.5$ & ND \\
\hline $\mathrm{SO}$ & Salvia officinalis (L.) & $>1.5$ & ND & $>1.5$ & ND \\
\hline SG & Swinglea glutinosa (Blanco) & $>1.5$ & ND & $>1.5$ & ND \\
\hline TL & Tagetes lucida (Cav.) & $1.5 \pm 0.07$ & $53.00 \pm 0.10$ & $1.5 \pm 0.02$ & $67.02 \pm 0.23$ \\
\hline TV & Thymus vulgaris (L.) & $0.37 \pm 0.7$ & $59.33 \pm 0.14$ & $0.37 \pm 0.10$ & $68.52 \pm 0.21$ \\
\hline SV & Satureja viminea (L.) & $>1.5$ & ND & $>1.5$ & ND \\
\hline $\mathrm{CO}$ & Cananga odorata (Lam.) & $>1.5$ & ND & $>1.5$ & ND \\
\hline
\end{tabular}




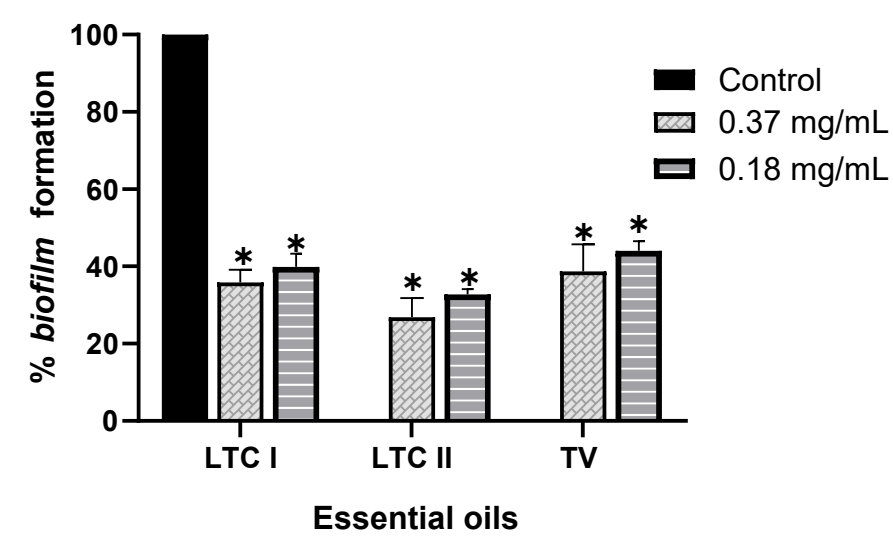

a

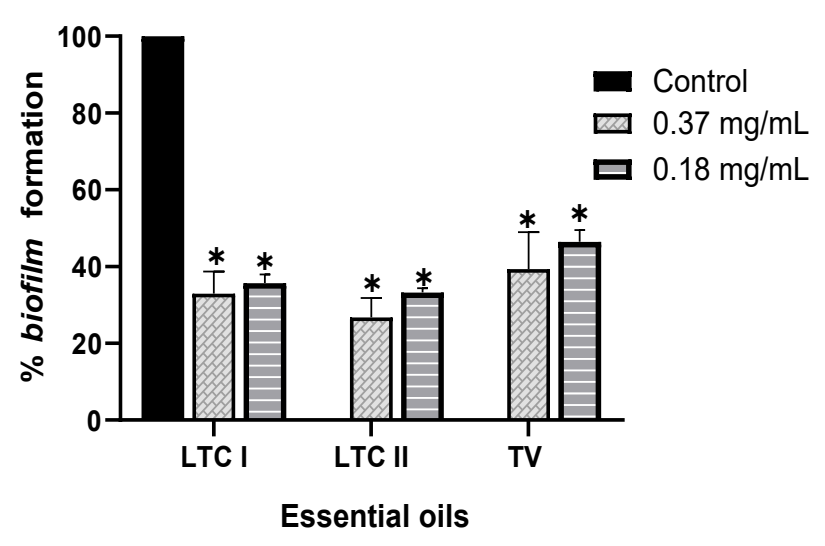

b

Figure 1. Effect of essential oils from L. origanoides (LTC I), L. origanoides (LTC II), and Thymus vulgaris (TV) on biofilm formation by S. enteritidis ATCC 13076 (a) and S. typhimurium ATCC 14028 (b). Data are represented as mean \pm SD. ANOVA was used to show statistically significant differences with respect to the control. ${ }^{*} p<0.05$.

\subsection{Scanning Electron Microscopy}

S. enteritidis and S. typhimurium biofilms showed differences in cell density and morphology when treated with the LTC II EO compared to the untreated control. As shown in Figure 2, the untreated biofilm of S. enteritidis consisted of smooth-bacillary cells with an average size of $1102 \pm 180 \mathrm{~nm}$, embedded in a dense extracellular polysaccharide matrix (Figure 2a). The biofilm treated with the EO showed dispersed and morphologically irregular cells with an average size of $1450 \pm 199 \mathrm{~nm}$, as well as a decrease in the exopolysaccharide matrix (Figure $2 \mathrm{~b}$ ). A similar effect can be observed in the biofilm of $S$. typhimurium, in which the abundant formation of biofilm and regular bacillary morphologies of cells were observed with an average size of $1869 \pm 395 \mathrm{~nm}$ (Figure 2c), whereas the biofilm treated with LTC II EO clearly shows cellular decrease and changes in bacterial morphology (Figure 2d).

\subsection{QS and Biofilm Formation Gene Expression Analysis}

RT-qPCR was used to evidence the influence of the EO from LTC II on the expression of genes involved in the QS signaling pathway and biofilm formation in sessile and planktonic cells of Salmonella (Figure 3).

Compared to the control, EO from LTC II most markedly inhibited the expression of curli genes $(\operatorname{csg} A, \operatorname{csg} B$, and $\operatorname{csg} D)$ in planktonic and sessile cells for both microorganisms. In addition, LTC II EO notably down-regulated the expression of the genes involved in cell motility (swimming genes $m o t B$, flhD, and fliZ). Additionally, the genes involved in chemical cell communication were inhibited in Salmonella Typhimurium planktonic cells and in Enteritidis and Typhimurium biofilm cells, whereas the luxR gene in Salmonella Enteritidis planktonic cells was up-regulated.

It has been previously reported that curli fimbriae are important for biofilm formation because they promote surface colonization and cell-cell interactions [26]. In addition, motility-related genes allow bacteria to develop active motility mechanisms that enable them to reach the surface of the culture medium and counteract hydrophobic interaction [27]. These results indicate that LTC II EO reduces the expression of genes related to primary adherence and motility, leading to the inhibition of the biofilm formation of S. enteritidis and S. typhimurium. 


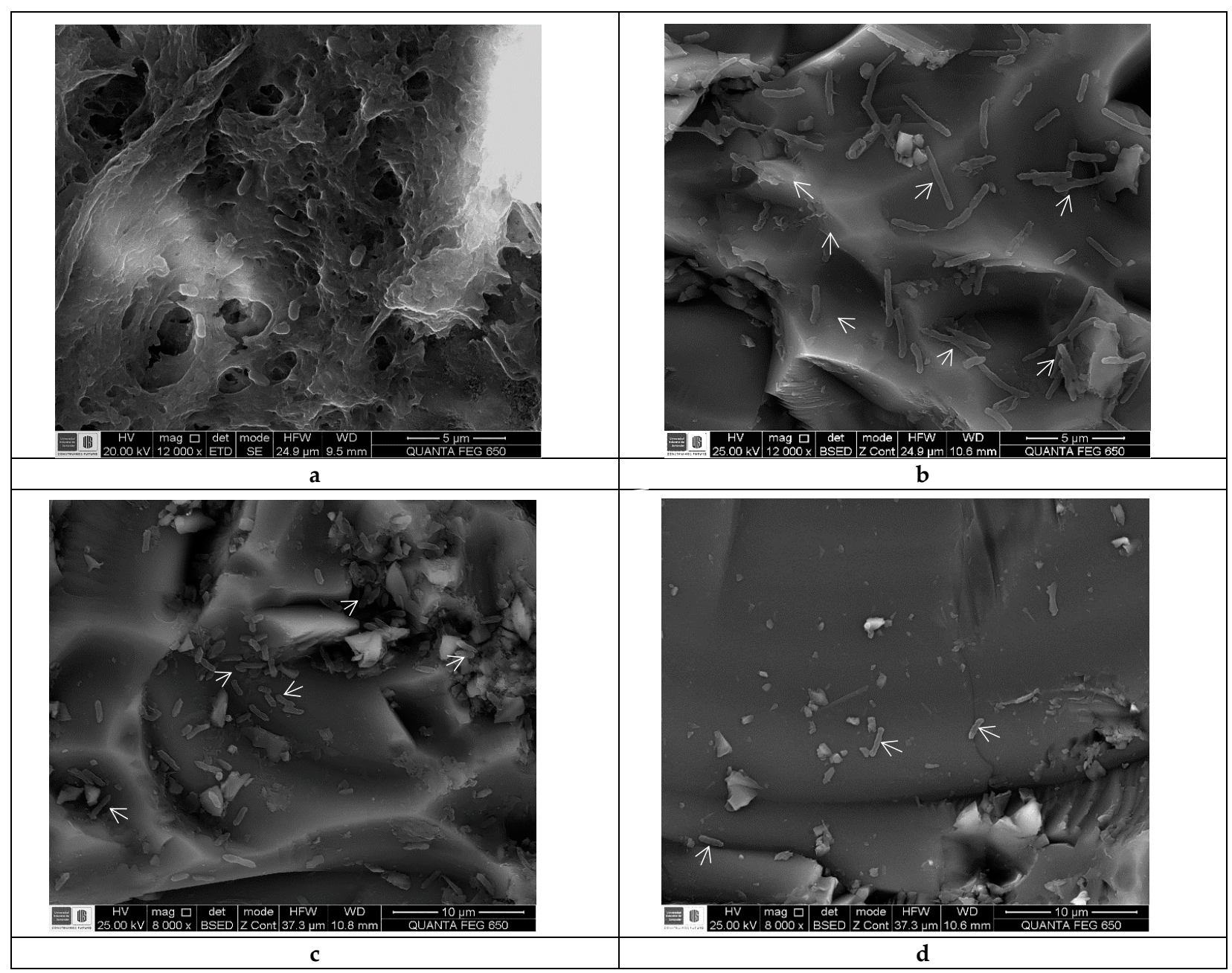

Figure 2. SEM micrographs of S. enteritidis and S. typhimurium biofilms formed on ground-glass coupons. (a) Non-treated S. enteritidis biofilm (control). (b) S. enteritidis biofilm treated with sub-inhibitory concentrations of EO from LTC II. (c) Nontreated S. enteritidis biofilm (control). (d) S. typhimurium biofilm treated with sub-inhibitory concentrations of EO from LTC II. Arrow indicates some bacteria.

a

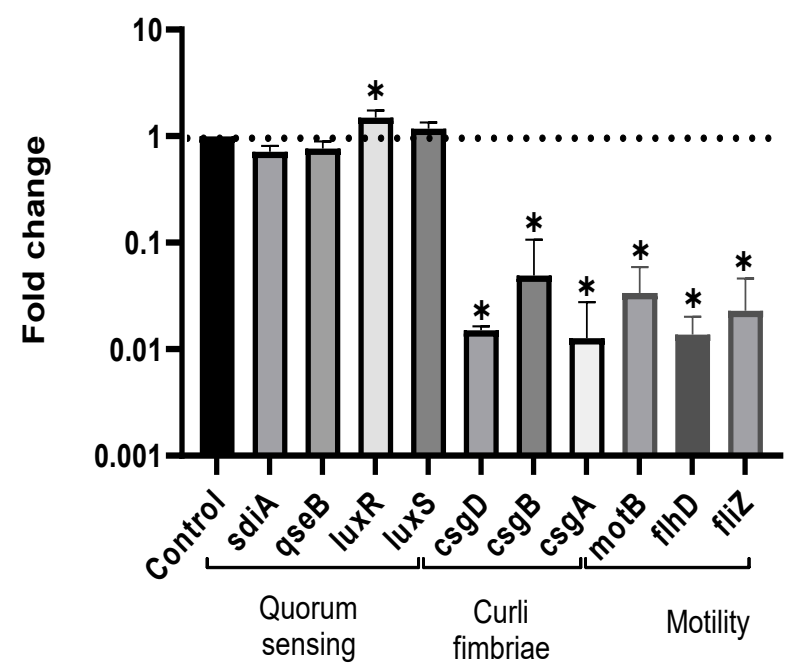

b

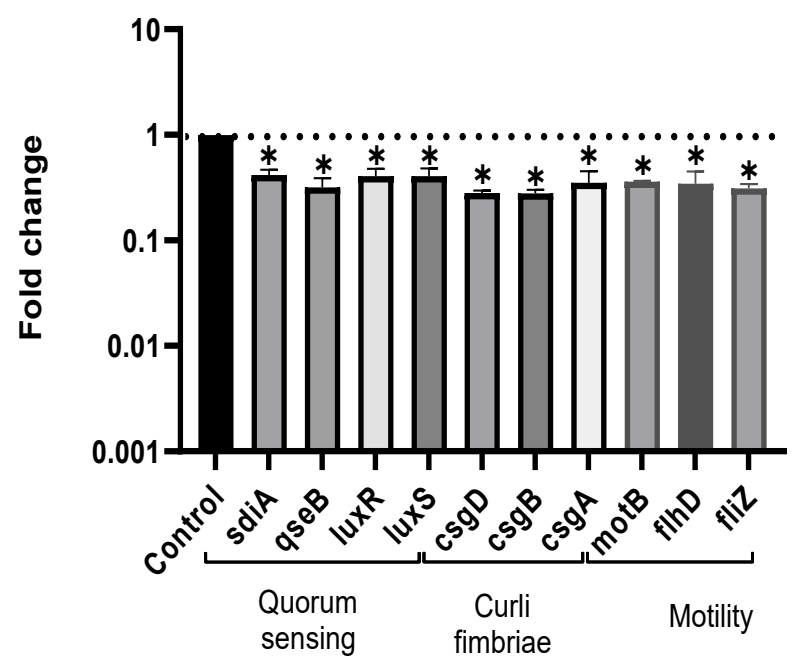

Figure 3. Cont. 
C

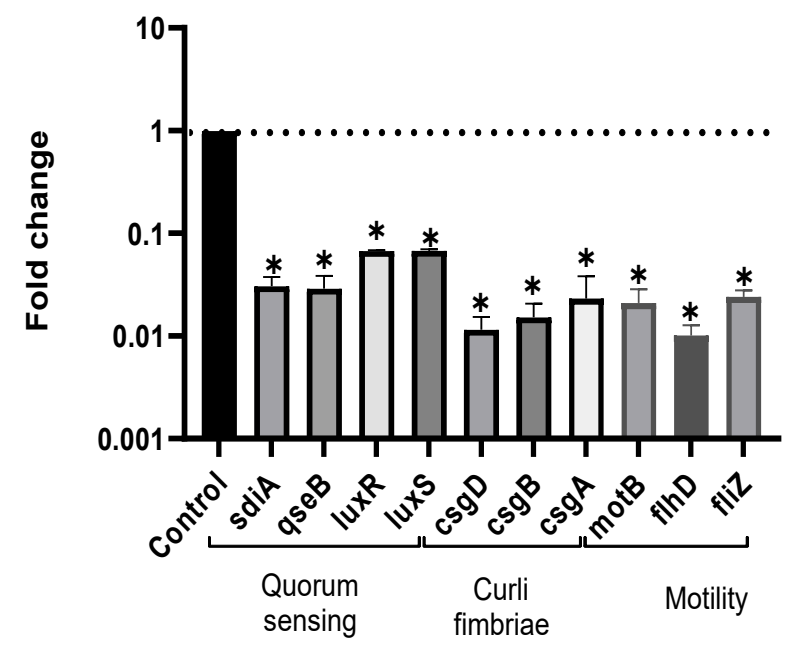

d

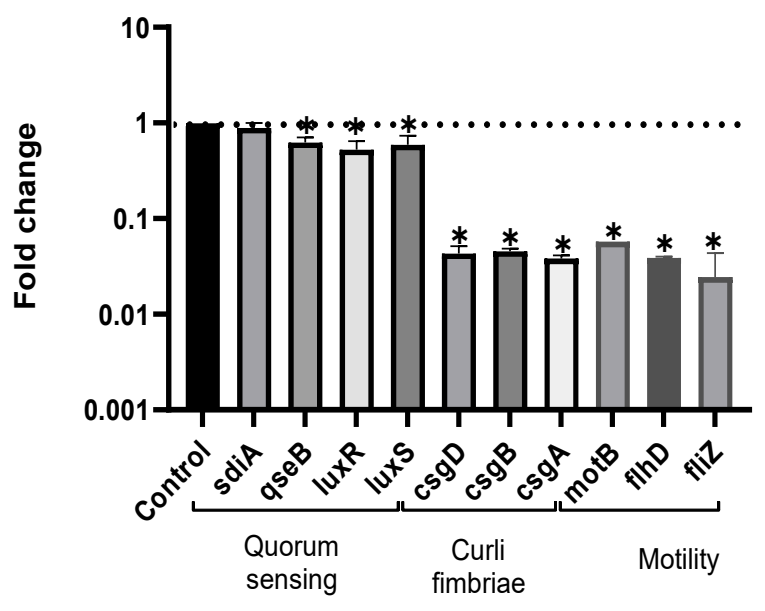

Figure 3. Expression profiles of QS genes in planktonic (a) and biofilm-associated cells (b) of S. enteritidis, and in planktonic (c) and biofilm-associated cells (d) of S. typhimurium treated or not treated with LTC II EO. The relative expression of the target genes was normalized to the gst reference gene. Bars represent standard deviation. ANOVA was used to show statistically significant differences with respect to the control. ${ }^{*} p<0.05$.

\section{Discussion}

Non-typhoidal salmonellosis infection is a worldwide problem. The lack of effective therapies, multi-resistance to antibiotics, and the ability to form biofilm are some of the main causes of the increase in the prevalence of bacterial diseases [28]. Therefore, it is necessary to find new antimicrobial agents that mitigate the resistance of high-incidence pathogens, such as Salmonella.

In this study, the antimicrobial and anti-biofilm effects of 15 EOs were evaluated on Salmonella enterica serovar Enteritidis ATCC 13076 and Salmonella enterica serovar Typhimurium 14028. It has been demonstrated that EO antimicrobial activity is caused by their chemical composition, the functional groups present in the active components, and synergistic interactions between the compounds [29]. EOs that obtained a higher antibacterial activity had a high content of phenolic compounds, such as thymol (EOs from LTC I, LTC II, and TV) and carvacrol (EOs from LTC I and LTC II) (Table 3). The mechanism of action of these compounds consists of the permeabilization of the bacterial cell membrane, followed by the loss of ions and membrane potential, which causes the collapse of proton pumps and the depletion of the adenosine triphosphate group of ATP, with consequent delays or inhibitions in microbial growth [30,31]. Other authors such as Sarrazin et al. have confirmed the antimicrobial effect of L. origanoides EO on food-borne microorganisms, attributing its antimicrobial activity to oxygenated compounds [32]. Additionally, they inferred that the antimicrobial activity of EOs may be the result of the interactions of all EOs components-thus, for example, $p$-cymene (biosynthetic precursor of these compounds) is not an efficient antimicrobial agent when it is individually used, but its presence in the EOs potentiates the action of other components of EOs [32].

Boskovic et al. determined the MIC of the TV EO on S. enteritidis ATCC 13076 and S. typhimurium ATCC 14028, obtaining similar results to those reported in this study $\left(\mathrm{MIC}=0.32 \mathrm{mg} \mathrm{mL}^{-1}\right)$ [33]. Moreover, CM EO also showed antimicrobial activity against S. enteritidis and S. typhimurium, which has been associated with a high content of oxygenated monoterpenes, such as geraniol [34], a compound that has been widely studied to determine its antimicrobial properties [35]. 
Table 3. Major chemical constituents present in the EOs assessed. Relative amount of each metabolite is reported as a percentage $(\%)$.

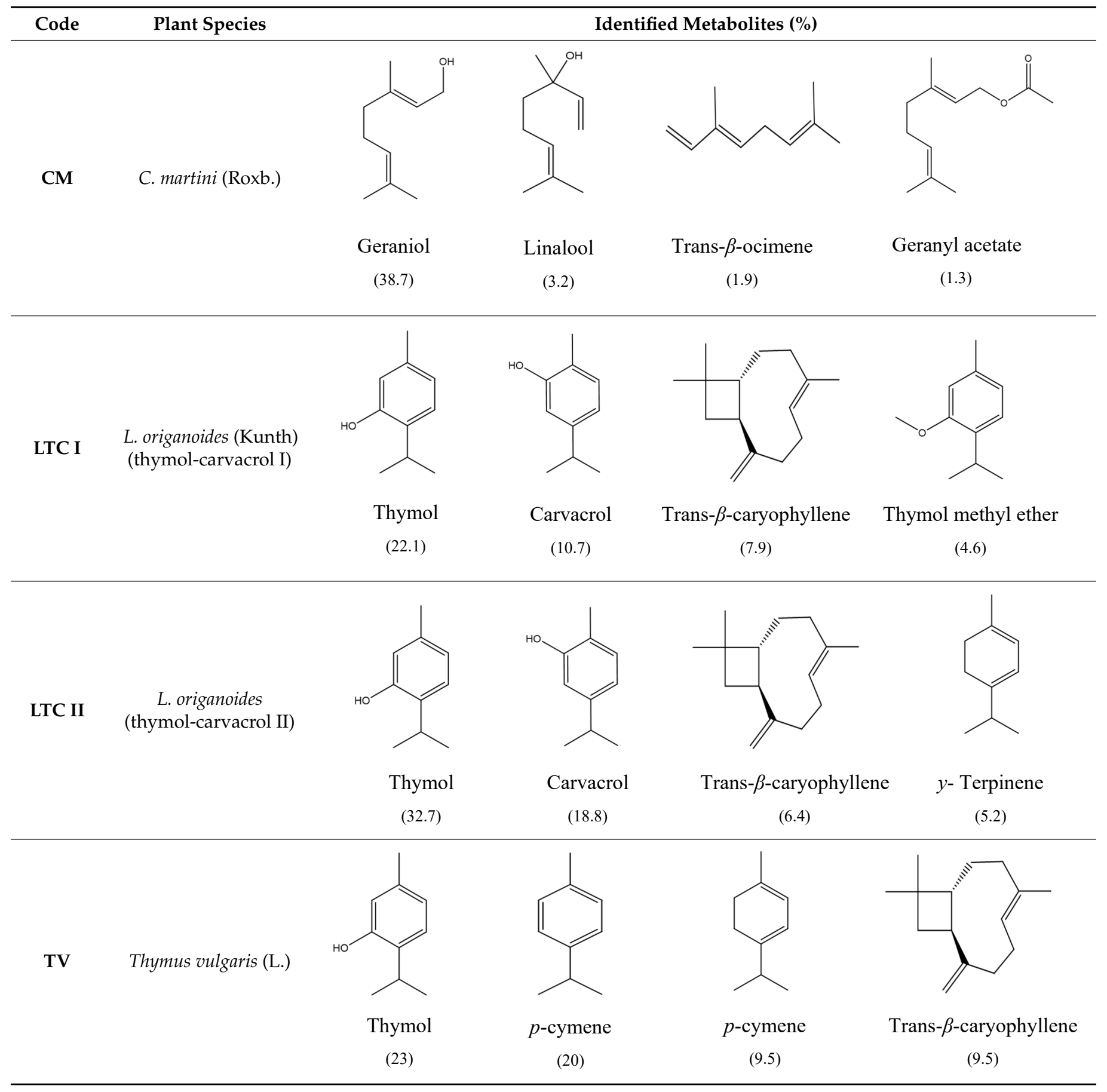

In our study, TV and CM EOs also inhibited the formation of the biofilm of S. enteritidis and S. typhimurium by $60 \%$ at sub-inhibitory concentrations. Further, in this study we report for the first time the anti-biofilm activity of the TL and LOF EOs against Salmonella. The antimicrobial and anti-biofilm activities of several of the major compounds of these EOs, such as estragole and 1-8 cineole, have been studied on various microorganisms [36].

One possible mechanism of action of EOs on biofilm has been attributed to the ability of EOs to diffuse through the EPS matrix, allowing interaction with bacterial membrane proteins and decreasing the binding of planktonic cells to surfaces $[37,38]$. Another reported 
mechanism is the reduction in motility and the interference of the production of adhesins or appendages such as curli proteins and flagella [38].

Transcriptional assays made it possible to establish that LTC II EO was able to inhibit the expression of genes related to the production of curli fimbriae, a key protein component of biofilms [39]. Both curli fimbrae and cellulose synthesis are co-regulated through the gene $\operatorname{csg} D$. Thus, the inhibition of expression of $\operatorname{csg} D$ genes will inhibit cellulose production through the $a d r A$ regulator gene [26,40], which is consistent with the decrease in or absence of exo-polysaccharide matrix observed in SEM images (Figure 3b-d). Additionally, EOs inhibited the gene expression of $m o t \mathrm{~B}, f l i z$, and $f l h D$, related to cell motility, reducing the bacterial capacity to produce biofilm. These results are consistent with those obtained by Inamuco et al., who proved that carvacrol was able to inhibit the motility of Salmonella Typhimurium at sub-inhibitory concentrations [41].

Moreover, LTC II inhibited the expression of the sdiA, luxS, and luxR genes implicated in QS. This effect could be related to the inhibition of the biosynthesis of signal molecules or the blocking of the reception of acyl homoserine lactone. At the same time, it is possible that molecules cause enzyme inactivation and the biodegradation of molecules involved in QS [42]. On the other hand, it is essential to carry out other omics studies to corroborate the metabolic pathways involved in QS.

These results prove the biological potential of EOs, mainly from LTC II, in the inhibition of sessile and planktonic cells from S. enteritidis and S. typhimurium, probably by means of the negative regulation of genes implicated in the production of proteins involved in both cell adherence and motility and QS. Moreover, EOs could also decrease the pathogenesis of Salmonella by the negative regulation of curli gene expression [43].

\section{Materials and Methods}

\subsection{Plant Material}

The EOs used in this study were previously reported by (Cáceres et al., 2020). Fifteen EOs were obtained from experimental crops at the CENIVAM Pilot Agro-industrial complex ( $07^{\circ} 08^{\prime} 442^{\prime \prime}$; W $73^{\circ} 06^{\prime} 960^{\prime \prime}$; 977 a.m.s.l.). The EOs were extracted by hydrodistillation in Clevenger-type equipment adapted to a Samsung microwave heating system, MS-1242zk (Seoul, Korea oven with an output power of $1600 \mathrm{~W}$ and a $2.4 \mathrm{GHz}$ radiation frequency). The obtained EOs were dried over anhydrous sodium sulfate, weighed, and stored at $4{ }^{\circ} \mathrm{C}$. All of the extractions were carried out in triplicate [44].

\subsection{Bacterial Strains and Growth Conditions}

Salmonella enterica serovar Typhimurium (S. typhimurium) ATCC 14028 and Salmonella enterica serovar Enteritidis (S. enteritidis) ATCC 13076 strains were obtained from the American Type Culture Collection (ATCC; Rockville, MD, USA). Before carrying out the antimicrobial and anti-biofilm experiments, both Salmonella strains were grown in M63 medium [45] at $37^{\circ} \mathrm{C}$.

\subsection{Determination of the In Vitro Antimicrobial Activity of EOs on Planktonic Cells}

The antimicrobial effects of the $15 \mathrm{EOs}$ were determined using the broth microdilution method (CLSI, 2015). The evaluation of the minimum inhibitory concentration (MIC) and minimum bactericidal concentration (MBC) was carried out as reported previously [23]. The inoculum used in the antimicrobial activity tests consisted of cultures prepared in M63 medium for $12 \mathrm{~h}$ at $37^{\circ} \mathrm{C}$ with constant agitation at $200 \mathrm{rpm}$ [45]; these were adjusted until a concentration of $\sim 5 \times 10^{6} \mathrm{CFU} \mathrm{mL}^{-1}$ was reached. Then, $100 \mu \mathrm{L}$ of the inoculum was mixed with $100 \mu \mathrm{L}$ of EO dissolved in $1 \%(v / v)$ DMSO in microplates for final concentrations of $0.18,0.37,0.75$, and $1.5 \mathrm{mg} \mathrm{mL}^{-1}$. Microplates were incubated at $37^{\circ} \mathrm{C}$ with constant agitation at $200 \mathrm{rpm}$. Microbial growth measurements were carried out at $595 \mathrm{~nm}$ every hour for $24 \mathrm{~h}$ in an ELISA microplate reader spectrophotometer (Biorad, imarck version 1.02.01, Hercules, CA, USA). After $24 \mathrm{~h}$ of culture in the presence of $\mathrm{EO}, 100 \mu \mathrm{L}$ aliquots from each well were mixed with $900 \mu \mathrm{L}$ of BHI medium in sterile tubes and incubated at $37^{\circ} \mathrm{C}$ 
for $24 \mathrm{~h}$ (INE-500; Memmert, Schwabach, Germany). Then, a $10 \mu \mathrm{L}$ aliquot was streaked on BHI agar plates to confirm the bactericidal effect. The MBC value was determined as the concentration at which $100 \%$ of the bacterial growth is completely inhibited compared to a control not treated with EOs. The antibiotic ofloxacin was used as a positive control of microbial inhibition for MIC and MBC. MIC is defined as the lowest concentration of EO at which an inhibition in the growth of the bacteria occurs.

\subsection{In Vitro Inhibition of Biofilm Formation}

The evaluation of the in vitro inhibition of biofilm formation was carried out according to the method described by Molhoek, with some modifications [46]. Bacterial strains were grown overnight in M63 medium at $37^{\circ} \mathrm{C}$ and diluted in fresh medium (1:10). Then, $100 \mu \mathrm{L}$ of cells was added to sterile 96 -well flat-bottom polystyrene microplates containing sub-inhibitory concentrations (subMIC) of the EOs. Microplates were incubated at $37^{\circ} \mathrm{C}$ for $24 \mathrm{~h}$ without shaking. Biofilm biomass was quantified using the crystal violet staining method. The microplates were washed three times with sterile phosphate buffer saline (PBS, $1 \mathrm{mM} \mathrm{pH} \mathrm{7)} \mathrm{to} \mathrm{remove} \mathrm{free-floating} \mathrm{planktonic} \mathrm{bacteria.} \mathrm{Then,} 200 \mu \mathrm{L}$ of $0.4 \%(w / v)$ crystal violet was added to each of the wells for $15 \mathrm{~min}$. Crystal violet excess was eliminated by three consecutive washes with sterile phosphate buffer saline (PBS, $1 \mathrm{mM} \mathrm{pH} \mathrm{7)} \mathrm{and}$ $200 \mu \mathrm{L}$ of $30 \%(v / v)$ acetic acid was then added to remove the adhered dye. The contents of each well were transferred to a new microplate to quantify the absorbance at $595 \mathrm{~nm}$ in an ELISA microplate reader [45].

\subsection{Scanning Electron Microscopy}

Scanning electron microscopy (SEM) was used to visualize the effect of EOs on S. typhimurium ATCC 14028 and S. enteritidis ATCC 13076. An inoculum of each of the strains was prepared by culturing them in M63 medium for $12 \mathrm{~h}$ at $37^{\circ} \mathrm{C}$ and orbital shaking at $200 \mathrm{rpm}$, until a concentration of $\sim 5 \times 10^{6} \mathrm{CFU} \mathrm{mL}{ }^{-1}$ was reached. Then, $1 \mathrm{~mL}$ of bacterial inoculum was added to a $40 \mathrm{~mL}$ aerated batch bioreactor containing $9 \mathrm{~mL}$ of fresh M63 medium, a $2 \times 5 \mathrm{~cm}$ ground-glass coupon, and the EO at a sub-inhibitory concentration. Cultures were conducted for $24 \mathrm{~h}$ at $37^{\circ} \mathrm{C}$. Coupons were washed three times with $0.1 \mathrm{mM}$ of phosphate buffer after incubation to eliminate planktonic cells. Biofilmassociated cells were fixed with $2.5 \%(v / v)$ glutaraldehyde for $60 \mathrm{~min}$ and dehydrated using an isopropanol gradient (10 to $95 \%$ ) for $10 \mathrm{~min}$ [47]. Finally, the coupons were observed in a Quanta 650 FEG electron microscope (FEI, Hillsboro, OR, USA) equipped with an Everhart Thornley ETD image detector.

\subsection{RNA Extraction and Transcriptional Analysis}

The formation and inhibition of biofilm assays were carried out in aerated bioreactors containing $40 \mathrm{~mL}$ of M63 medium, a $2 \times 5 \mathrm{~cm}$ ground-glass coupon, and the EO at a sub-inhibitory concentration, which were inoculated with $\sim 5 \times 10^{6} \mathrm{CFU} \mathrm{mL}^{-1}$ of each of the strains. Cultures were conducted for $24 \mathrm{~h}$ at $37^{\circ} \mathrm{C}$. The coupon was washed with sterile phosphate buffer saline (PBS, $1 \mathrm{mM} \mathrm{pH} \mathrm{7)} \mathrm{to} \mathrm{remove} \mathrm{planktonic} \mathrm{cells} \mathrm{and} \mathrm{biofilm-associated}$ cells were then harvested for RNA extraction using sterile spatulas. Total RNA was isolated using a PureLink RNA Mini Kit (Ambion, Life Technologies, Carlsbad, CA, USA). The RNA purity and quality were verified using an NP80 Nanophotometer (IMPLEN, München, Germany) and cDNA synthesis from RNA was performed with the RevertAid ${ }^{\mathrm{TM}} \mathrm{H}$ Minus First Strand cDNA synthesis kit (Fermentas, Thermo Fisher Scientific, Madison, WI, USA).

RT-qPCR assays were carried out using the Sybr green-based Luna ${ }^{\circledR}$ Universal qPCR Master Mix (New England Biolabs, Ipswich, MA, USA) in a CFX96 ${ }^{\mathrm{TM}}$ Real-Time PCR Detection System (Bio-Rad, Hercules, CA, USA). According to the manufacturer's instructions, reactions were prepared with a final volume of $20 \mu \mathrm{L}$ containing $1 \mathrm{X}$ master mix, $0.25 \mu \mathrm{M}$ of each primer, $100 \mathrm{ng}$ template cDNA, and water. The amplification programs consisted of an initial denaturing at $95^{\circ} \mathrm{C}$ for $1 \mathrm{~min}$, followed by 40 cycles of $95^{\circ} \mathrm{C}$ for $15 \mathrm{~s}, 55-60{ }^{\circ} \mathrm{C}$ for $45 \mathrm{~s}$. Negative controls (NTC) consisted of omitting any cDNA template from the 
reaction. The relative expression of the genes involved in Salmonella QS cell signaling, such as sdiA, luxR (encoding the autoinducer 1-AI-1), luxS (encoding the autoinducer 2-AI-2), and QseB (encoding the response regulator); curli genes, such as $\operatorname{csg} A$ (curli subunit, major curli subunit), $\operatorname{csg} B$ (curli nucleator protein curli), and $\operatorname{csg} D$ (transcriptional activator for csgBA); motility genes fliZ (flagellar biosynthesis regulator FliA), flhD (flagellar biosynthesis regulator), and $\operatorname{mot} B$ (flagellar rotation generator), were determined using the glutathione transferase ( $g s t)$ and 6-phosphoglucanate dehydrogenase (gnd) genes as a reference for normalization. The Primer3 software [48] and OligoCalc [49] were used to design gene-specific primers, as shown in Table 4. A gene expression and efficiency calculation was performed using the $2^{-\Delta \Delta \mathrm{Ct}}$ method [50].

Table 4. List of primers used for amplification.

\begin{tabular}{ccc}
\hline Genes & Forward $\left(\mathbf{5}^{\prime} \mathbf{- \mathbf { 3 } ^ { \prime } )}\right.$ & Reverse $\left(\mathbf{3}^{\prime} \mathbf{- 5}^{\prime} \mathbf{)}\right.$ \\
\hline$g n d$ & ACGCAGAAAACGCTGGTATC & CCACTCGGTATGGAAAATGC \\
$g s t$ & TGTGGATGAGTCGCTTTCAG & GCAACGGTCGGTCTTTTT \\
$s d i A$ & GTCATCCCGTCCCCTTTAC & GGTTCGGCAACATCACAC \\
$l u x R$ & GATTGCTGCCCTCTGTTTTC & CGGCTTCTTCCAGTGAAT \\
$l u x S$ & CGACCACCTCAACGGTAA & GCACATCACGCTCCAGAATA \\
$Q s e B$ & GCGAAAAGGGTAAACAGG & CGCAGTAAGAGTTCCAGCA \\
$c s g A$ & ATGCCCGTAAATCTGAAACG & ACCAACCTGACGCACCATTA \\
$c s g B$ & CGCATGTCGCTAACAAGGTA & ATTATCCGTGCCGACTTGAC \\
$c s g D$ & GATGGAAGCGGATAAGAAGC & GACTCGGTGCTGTTGTAGC \\
$f l i z$ & CGGTTTCAAGCAGTATTTGT & CGGTAAAGGGGGATTTCTG \\
$f l h D$ & TTCCGCCTCGGTATCAAC & GCCGTATCGTCCACTTCATT \\
$m o t B$ & AGTGGAAAAGCAGCCGAATA & GCAACCCCTCCTGAACTAAA \\
\hline
\end{tabular}

\subsection{Statistical Analysis}

All results are expressed as means and their respective standard deviations for each of the assays. The Kolmogorov-Smirnov test [51] was used to verify the normality of the data and a maximum $F$ test to test the homogeneity of variance (ANOVA). All statistical analyses were performed on the R platform [52], considering $p<0.05$ as statistically significant. Significant changes are indicated by asterisks in the figures.

\section{Conclusions}

EOs with a higher content of oxygenated compounds exhibited greater antimicrobial and anti-biofilm activity than the other EOs used against S. enteritidis and S. typhimurium. EO isolated from the L. origanoides chemotype thymol-carvacrol (LTC II) showed the highest antimicrobial activity against both Salmonella strains, whereas LTC I and LTC II EOs displayed the highest anti-biofilm potential. These differences in antimicrobial activity can be attributed to changes in the expression of genes involved in biofilm formation, demonstrating that the EOs used in this study not only inhibited QS signaling, which would affect the processes of the initiation, maturation, and dispersion of the biofilm, but also modified the expression of genes involved in the adhesion, motility, and. production of EPS. Finally, the EOs used in this study represent a promising alternative for both microbial control and therapeutic treatment against pathogenic resistant bacteria. However, further studies are needed in order to elucidate the mechanisms of action of the essential oils on the bacterial cells under study.

Author Contributions: Conceptualization: Y.G. and M.C.; formal analysis: Y.G. and M.C.; investigation: M.C., E.S., and C.O.; methodology: Y.G., R.T., and E.S.; project administration: C.O.; supervision: R.T., E.S., and C.O.; writing—original draft, Y.G.: writing—review and editing, M.C., R.T., E.S., and C.O. All authors have read and agreed to the published version of the manuscript.

Funding: This research was funded by Colciencias (Colombia, Project number 1102-777-57586) and Universidad Industrial de Santander (Vicerrectoría de Investigación y Extension, project number 8742). 
Data Availability Statement: Data is contained within the article.

Acknowledgments: The authors gratefully acknowledge the financial support from Colciencias (Colombia, Project number 1102-777-57586) and Universidad Industrial de Santander (Vicerrectoría de Investigación y Extensión, project number 8742) and contract $\mathrm{N}^{\circ} 270$ for access to genetic resources and derived products for bioprospecting purposes, signed between the Ministry of Environment and Sustainable Development and Universidad Industrial de Santander. Authorization for the collection of wild species specimens from biological diversity for non-commercial scientific research purposes was granted by the National Environmental Licensing Authority-ANLA (Resolutions 00422 January, 2015 and 026011 March 11 2016).

Conflicts of Interest: The authors declare no competing financial interest.

\section{References}

1. Gast, R.K.; Porter, R.E. Salmonella infections. In Diseases of Poultry, 14th ed.; John Wiley and Sons: Hoboken, NJ, USA, 2020; pp. 717-753.

2. Quesada, A.; Reginatto, G.A.; Español, A.R.; Colantonio, L.D.; Burrone, M.S. Resistencia antimicrobiana de Salmonella spp aislada de alimentos de origen animal para consumo humano. Rev. Peru. Med. Exp. Salud Publica 2016, 33, 32-44. [CrossRef]

3. Rukambile, E.; Sintchenko, V.; Muscatello, G.; Kock, R.; Alders, R. Infection, colonization and shedding of Campylobacter and Salmonella in animals and their contribution to human disease: A review. Zoonoses Public Health 2019, 66, 562-578. [CrossRef] [PubMed]

4. Piatek, J.; Sommermeyer, H.; Bernatek, M.; Ciechelska-Rybarczyk, A.; Oleskow, B.; Mikkelsen, L.; Barken, K. Persistent infection by Salmonella enterica servovar Typhimurium: Are synbiotics a therapeutic option?-A case report. Benef. Microbes 2019, 10, 211-217. [CrossRef] [PubMed]

5. CDC. Antibiotic resistance threats in the United States. Centers Dis. Control Prev. 2019, 114.

6. WHO. Global Antimicrobial Resistance and Use Surveillance System (GLASS) Report; World Health Organization: Geneva, Switzerland, 2020.

7. Hall, C.W.; Mah, T.F. Molecular mechanisms of biofilm-based antibiotic resistance and tolerance in pathogenic bacteria. FEMS Microbiol. Rev. 2017, 41, 276-301. [CrossRef]

8. Sultan, I.; Rahman, S.; Jan, A.T.; Siddiqui, M.; Mondal, A.; Haq, Q. Antibiotics, resistome and resistance mechanisms: A bacterial perspective. Front. Microbiol. 2018, 9, 2066. [CrossRef]

9. Sharma, V.K.; Johnson, N.; Cizmas, L.; Mcdonald, T.J.; Kim, H. A review of the influence of treatment strategies on antibiotic resistant bacteria and antibiotic resistance genes. Chemosphere 2016, 150, 702-714. [CrossRef]

10. Chylkova, T.; Cadena, M.; Ferreiro, A.; Pitesky, M. Susceptibility of Salmonella biofilm and planktonic bacteria to common disinfectant agents used in poultry processing. J. Food Prot. 2017, 80, 1072-1079. [CrossRef]

11. Wang, J.; Ding, L.; Li, K.; Huang, H.; Hu, H.; Geng, J.; Xu, K.; Ren, H. Estimation of spatial distribution of quorum sensing signaling in sequencing batch biofilm reactor (SBBR) biofilms. Sci. Total Environ. 2018, 612, 405-414. [CrossRef]

12. Eng, S.; Pusparajah, P.; Ab Mutalib, N.; Ser, H.; Chan, K.; Lee, L.H. Salmonella: A review on pathogenesis, epidemiology and antibiotic resistance. Front. Life Sci. 2015, 8, 284-293. [CrossRef]

13. Verderosa, A.; Totsika, M.; Fairfull-smith, K. Bacterial Biofilm Eradication Agents: A Current Review. Front. Chem. 2019, 7, 824. [CrossRef]

14. Steenackers, H.; Hermans, K.; Vanderleyden, J.; De Keersmaecker, S. Salmonella biofilms: An overview on occurrence, structure, regulation and eradication. Food Res. Int. 2012, 45, 502-531. [CrossRef]

15. Singh, S.; Singh, S.K.; Chowdhury, I.; Singh, R. Understanding the Mechanism of Bacterial Biofilms Resistance to Antimicrobial Agents. Open Microbiol. J. 2017, 11, 53-62. [CrossRef] [PubMed]

16. Yan, J.; Bassler, B. Surviving as a Community: Antibiotic Tolerance and Persistence in Bacterial Biofilms. Cell Host Microbe 2019, 26, 15-21. [CrossRef] [PubMed]

17. Moraes, J.O.; Cruz, E.A.; Souza, E.G.F.; Oliveira, T.C.M.; Alvarenga, V.O.; Peña, W.E.L.; Sant'Ana, A.S.; Magnani, M. Predicting adhesion and biofilm formation boundaries on stainless steel surfaces by five Salmonella enterica strains belonging to different serovars as a function of $\mathrm{pH}$, temperature and $\mathrm{NaCl}$ concentration. Int. J. Food Microbiol. 2018, 281, 90-100. [CrossRef]

18. Pande, V.; McWhorter, A.; Chousalkar, K. Salmonella enterica isolates from layer farm environments are able to form biofilm on eggshell surfaces. Biofouling 2016, 32, 699-710. [CrossRef]

19. Alibi, S.; Ben, W.; Ramos-vivas, J.; Ali, M.; Touati, R.; Boukadida, J.; Navas, J.; Ben, H. Anti-oxidant, antibacterial, anti-biofilm, and anti-quorum sensing activities of four essential oils against multidrug-resistant bacterial clinical isolates. Curr. Res. Transl. Med. 2020, 68, 59-66. [CrossRef] [PubMed]

20. Leal, A.; Braga, A.; de Araujo, B.; Rodriguez, A.; de Carcalho, A.; da Silva, K.; Junio, E.; de Sousa Leite, T.; Amorim, M. Antimicrobial action of essential oil of Lippia origanoides HBK. Clin. Microbiol. Biochem. Technol. 2019, 5, 7-12. [CrossRef]

21. Čabarkapa, I.; Čolović, R.; Đuragić, O.; Popović, S.; Milanov, D.; Pezo, L. Anti-biofilm activities of essential oils rich in carvacrol and thymol against Salmonella Enteritidis. Biofouling 2019, 35, 361-375. [CrossRef] 
22. Swamy, M.; Akhtar, M.; Sinniah, U. Antimicrobial properties of plant essential oils against human pathogens and their mode of action: An updated review. Evid.-Based Complement. Altern. Med. 2016, 2016. [CrossRef]

23. Cáceres, M.; Hidalgo, W.; Stashenko, E.; Torres, R.; Ortiz, C. Essential Oils of Aromatic Plants with Antibacterial, Anti-Biofilm and Anti-Quorum Sensing Activities against Pathogenic Bacteria. Antibiotics 2020, 9, 147. [CrossRef]

24. Lambert, R.J.W.; Skandamis, P.N.; Coote, P.J.; Nychas, G.E. A study of the minimum inhibitory concentration and mode of action of oregano essential oil, thymol and carvacrol. J. Appl. Microbiol. 2001, 91, 453-462. [CrossRef] [PubMed]

25. Ouhayoun, J.P. Penetrating the plaque biofilm: Impact of essential oil mouthwash. J. Clin. Periodontol. 2003, 30, 10-12. [CrossRef]

26. Jonas, K.; Tomenius, H.; Kader, A.; Normark, S.; Römling, U.; Belova, L.; Melefors, Ö. Roles of curli, cellulose and BapA in Salmonella biofilm morphology studied by atomic force microscopy. BMC Microbiol. 2007, 7, 1-9. [CrossRef]

27. Lasa, I.; Del Pozo, J.L.; Leiva, J.; Penadés, J.R. Bacterial biofilms and infection. An. Sist. Sanit. Navar. 2005, 28, 163-175. [CrossRef]

28. Crump, J.A.; Heyderman, R.S. A perspective on invasive Salmonella disease in Africa. Clin. Infect. Dis. 2015, 61, S235-S240. [CrossRef] [PubMed]

29. Chouhan, S.; Sharma, K.; Guleria, S. Antimicrobial Activity of Some Essential Oils—Present Status and Future Perspectives. Medicines 2017, 4, 58. [CrossRef] [PubMed]

30. Kachur, K.; Suntres, Z. The antibacterial properties of phenolic isomers, carvacrol and thymol. Crit. Rev. Food Sci. Nutr. 2020, 60, 3042-3053. [CrossRef] [PubMed]

31. Gyawali, R.; Ibrahim, S.A. Natural products as antimicrobial agents. Food Control 2014, 46, 412-429. [CrossRef]

32. Sarrazin, S.L.F.; Da Silva, L.A.; Oliveira, R.B.; Raposo, J.D.A.; Da Silva, J.K.R.; Salimena, F.R.G.; Maia, J.G.S.; Mourão, R.H.V. Antibacterial action against food-borne microorganisms and antioxidant activity of carvacrol-rich oil from Lippia origanoides Kunth. Lipids Health Dis. 2015, 14, 1-8. [CrossRef]

33. Boskovic, M.; Zdravkovic, N.; Ivanovic, J.; Janjic, J.; Djordjevic, J.; Starcevic, M.; Baltic, M. Antimicrobial Activity of Thyme (Tymus vulgaris) and Oregano (Origanum vulgare) Essential Oils against Some Food-borne Microorganisms. Procedia Food Sci. 2015, 5, 18-21. [CrossRef]

34. Duarte, M.; Leme, E.; Delarmelina, C.; Soares, A.; Figueira, G.; Sartoratto, A. Activity of essential oils from Brazilian medicinal plants on Escherichia coli. J. Ethnopharmacol. 2007, 111, 197-201. [CrossRef]

35. Silva, N.; Fernandes, A. Biological properties of medicinal plants: A review of their antimicrobial activity. J. Venom. Anim. Toxins Incl. Trop. Dis. 2010, 16, 402-413. [CrossRef]

36. Kifer, D.; Mužinić, V.; Klaric, M. Antimicrobial potency of single and combined mupirocin and monoterpenes, thymol, menthol and 1,8-cineole against Staphylococcus aureus planktonic and biofilm growth. J. Antibiot. 2016, 69, 689-696. [CrossRef]

37. Nostro, A.; Roccaro, A.S.; Bisignano, G.; Marino, A.; Cannatelli, M.A.; Pizzimenti, F.C.; Cioni, P.L.; Procopio, F.; Blanco, A.R. Effects of oregano, carvacrol and thymol on Staphylococcus aureus and Staphylococcus epidermidis biofilms. J. Med. Microbiol. 2007, 56, 519-523. [CrossRef] [PubMed]

38. Toyofuku, M.; Inaba, T.; Kiyokawa, T.; Obana, N.; Yawata, Y.; Nomura, N. Environmental factors that shape biofilm formation. Biosci. Biotechnol. Biochem. 2016, 80,7-12. [CrossRef] [PubMed]

39. Tursi, S.A.; Puligedda, R.D.; Szabo, P.; Nicastro, L.K.; Miller, A.L.; Qiu, C.; Gallucci, S.; Relkin, N.R.; Buttaro, B.A.; Dessain, S.K.; et al. Salmonella Typhimurium biofilm disruption by a human antibody that binds a pan-amyloid epitope on curli. Nat. Commun. 2020, 11, 1-13. [CrossRef] [PubMed]

40. Eran, Z.; Akçelik, M.; Yazıcı, B.C.; Özcengiz, G.; Akçelik, N. Regulation of biofilm formation by marT in Salmonella Typhimurium. Mol. Biol. Rep. 2020, 47, 5041-5050. [CrossRef] [PubMed]

41. Inamuco, J.; Veenendaal, A.K.J.; Burt, S.A.; Post, J.A.; Tjeerdsma-van Bokhoven, J.L.M.; Haagsman, H.P.; Veldhuizen, E.J.A. Sub-lethal levels of carvacrol reduce Salmonella Typhimurium motility and invasion of porcine epithelial cells. Vet. Microbiol. 2012, 157, 200-207. [CrossRef]

42. Alvarez, M.; Ortega, L.; Gutierrez, M.; Berna, A.; Rodriguez, I.; Gonzalez, G.; Ponce, A.; del R. Moreira, M.; Roura, S.; Ayala, J. Oregano essential oil-pectin edible films as anti-quorum sensing and food antimicrobial agents. Front. Microbiol. $2014,5,699$. [CrossRef]

43. Tursi, S.A.; Tükel, Ç. Curli-Containing Enteric Biofilms Inside and Out: Matrix Composition, Immune Recognition, and Disease Implications. Microbiol. Mol. Biol. Rev. 2018, 82, 1-18. [CrossRef]

44. Stashenko, E.E.; Martínez, J.R.; Ruíz, C.A.; Arias, G.; Durán, C.; Salgar, W.; Cala, M. Lippia origanoides chemotype differentiation based on essential oil GC-MS and principal component analysis. J. Sep. Sci. 2010, 33, 93-103. [CrossRef]

45. O'Toole, G.A. Microtiter Dish Biofilm Formation Assay. J. Vis. Exp. 2011, 353913. [CrossRef] [PubMed]

46. Molhoek, E.M.; van Dijk, A.; Veldhuizen, E.J.A.; Haagsman, H.P.; Bikker, F.J. A cathelicidin-2-derived peptide effectively impairs Staphylococcus epidermidis biofilms. Int. J. Antimicrob. Agents 2011, 37, 476-479. [CrossRef] [PubMed]

47. Fischer, E.R.; Hansen, B.T.; Nair, V.; Hoyt, F.H.; Dorward, D.W. Scanning Electron Microscopy. Curr. Protoc. Microbiol. 2012, $25,47$. [CrossRef]

48. Untergasser, A.; Cutcutache, I.; Koressaar, T.; Ye, J.; Faircloth, B.C.; Remm, M.; Rozen, S.G. Primer3—new capabilities and interfaces. Nucleic Acids Res. 2012, 40, e115. [CrossRef] [PubMed]

49. Kibbe, W.A. OligoCalc: An online oligonucleotide properties calculator. Nucleic Acids Res. 2007, 35, W43-W46. [CrossRef] [PubMed] 
50. Livak, K.J.; Schmittgen, T.D. Analysis of Relative Gene Expression Data Using Real- Time Quantitative PCR and the $2^{-\Delta \Delta C t}$ Method. Methods 2001, 25, 402-408. [CrossRef] [PubMed]

51. Massey, F.J. The Kolmogorov-Smirnov Test for Goodness of Fit. J. Am. Stat. Assoc. 1951, 46, 68-78. [CrossRef]

52. RStudio Team. RStudio: Integrated Development for R. RStudio; PBC: Boston, MA, USA, 2018. 